\title{
THERMAL Simulations BASED ON MACRO-MODELS
}

\author{
Václav Marek, Zdeněk Hájíček
}
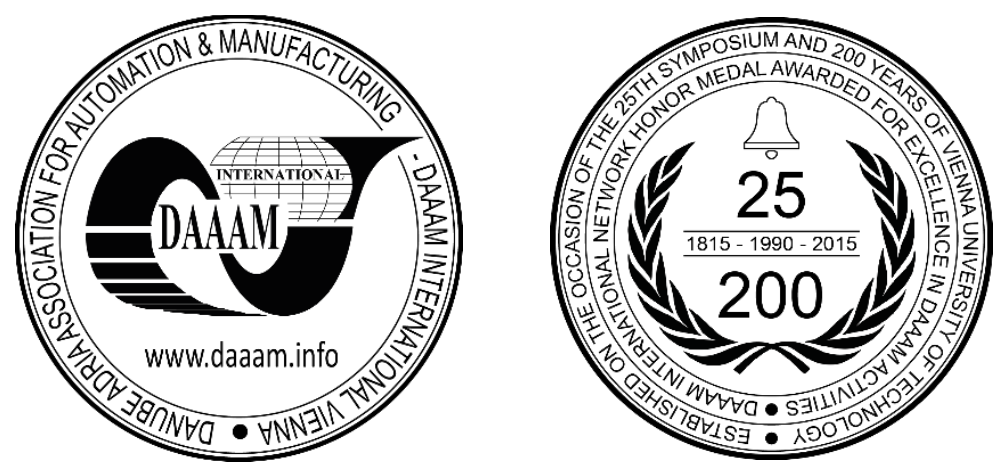

This Publication has to be referred as: Marek, V[aclav] \& Hajicek, Z[denek] (2017). Thermal Simulations Based on Macro-Models, Proceedings of the 28th DAAAM International Symposium, pp.0627-0634, B. Katalinic (Ed.), Published by DAAAM International, ISBN 978-3-902734-11-2, ISSN 1726-9679, Vienna, Austria DOI: $10.2507 / 28$ th.daaam.proceedings.089

\begin{abstract}
Thermal transfer simulations, computed fluid dynamic solutions and finite element methods in general are vital sources of information about behavior of machine parts with heat loading. All these methods have common disadvantages, which include the requirements of a skilled engineer, hardware and software, and generally the high cost of computation. These problems are solved in this article. The reduction of costs is solved by a new tool, which uses simple macro-elements with predefined, parametric properties. These elements are able to describe cooling channels, heat transfers in bodies or identify the temperatures of heat sources. Computation by macro-element method takes a significantly shorter time with suitable accuracy. The macro-element method is suitable for customizing in a wide spectrum of thermal transfer cases. The article defines macro-elements, describes their implementation and the verification of the method.
\end{abstract}

Keywords: thermal simulation; liquid-cooled spindle unit; macro-element method, thermal displacements

\section{Introduction}

Machine tools are highly sophisticated mechatronic systems enabling manufacturing processes at a given precision. A machine tool's precision strongly depends on its thermo-elastic behaviour [8]: Internal and external heat sources lead to a non-uniform and non-nominal temperature distribution resulting in elongation and mechanical deformations of the machine tool structure. One of the main factors in mastering the thermal behavior of machine tools is effective cooling. It can be achieved by conduction through solid parts, by radiation, by free or enforced convection on outer surfaces or by forced convection with liquid cooling systems. The non-uniform distribution leads to areas with higher thermal load, such as the main drive, the bearings or the cutting tool. Direct cooling of cutting tools is used in almost every cutting process. It provides cooling of the tool and lubricates the cutting area. In order to reduce thermally induced displacements, fluid based cooling systems are used. Main drives of machines can be cooled by air or by liquid circuits, while bearings are often cooled by liquid circuits and oil mist. Thus, controlling the thermo-elastic behavior of machine tools is to a large extent depending on the design of their fluidic system. In order to speed up the development and minimize the necessity of physical prototypes, it is essential to verify the design before manufacturing. Simulation of a complex system is laborious task: It requires time to prepare computer aided design (CAD) models, skilled employees and computation time.

This paper follows up an idea of macro-models. Weber describes the approach for a heat-loaded motorized spindle unit [5]. It uses a network based computation model. It describes the transient, three-dimensional energy exchange processes in built-in motorized spindles - especially in a cooling sleeve with a single helical rectangular water-cooling 
channel. [1] A similar approach is used by Institute of Machine Tools and Manufacturing (IWF), at ETH Zurich (the Swiss Federal Institute of Technology in Zurich). It is characterized by the description of a cooling channel as a series of predefined, but parametric geometric features. The tool predicts the heat transfer properties and pressure loss to be expected for a given operational point and coolant. According to the authors, the main advantage is the simplicity of use, and significantly shorter computation times than with a CFD approach [8].

\subsection{Current state}

The macro-element method is based on simple elements. Macro-elements are distinct elements, defined by elementary equations. The method produces a description of the properties of a fluid in one dimensional dependency. The properties of the macro-element depend on the properties of the fluid, the duct geometry and the operational point [1,2]. The properties of a wall like roughness also influence the results [9]. These dependencies determine pressure losses and heat transfer coefficients which are the two significant factors in cooling circuits. Macro-elements can be identified in Figure 1 , which shows a CFD simulation of a cooling circuit. It is a solved case of CFD simulation. The simulation consists of $2 \times 10^{5}$ elements, takes about 7 minutes and the solver uses a K-epsilon turbulent model of computation. This case is solved in NX10 simulation software. Examples of identified macro-elements are shown in table 1.

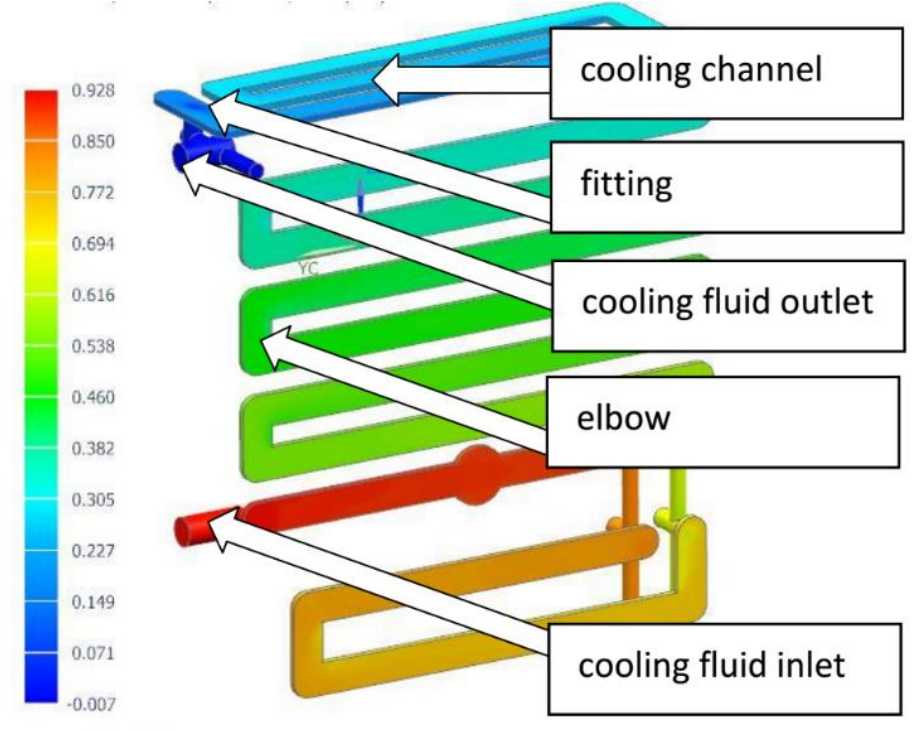

Units $=\mathrm{N} / \mathrm{mm} \wedge 2(\mathrm{MPa})$

Fig. 1. CFD simulation of pressure losses in cooling circuit (NX10)

Samples of identified macro-elements

\begin{tabular}{|c|c|}
\hline Channel & cooling channel, rectangular/circular \\
\hline Elbow & elbow element, rectangular/circular \\
\hline Helix channel & helix-shape cooling channel \\
\hline Flow-Around & element used for cooling of a bearings \\
\hline Fitting & connection, section change \\
\hline
\end{tabular}

\section{Pressure loss}

Table 1. Basic macro-elements

Macro-element definition consists of this pressure loss computation. Pressure loss is an important property of each macro-element. It is a necessary parameter for identifying the overall pressure loss in the cooling channel. The pressure loss $\Delta p$ depends on velocity $w$, density $\rho$ and friction coefficient $\zeta_{u}$.

$$
\Delta p=\zeta_{u} \frac{\rho w^{2}}{2}[P a]
$$

According to [4].

The friction coefficient is computed empirically:

$$
\zeta_{u}=f(R e, D, r)
$$


with the Reynolds number

$$
R e=\frac{w D}{v}
$$

and the pipe hydraulic diameter $D$ of the pipe, the kinematic viscosity $v$.

\section{Verification of pressure losses}

Calculations of properties are executed in order to define the basic shapes of each macro-element. The theoretical properties of the macro-elements presented in [2] were stated by using the equation for laminar and turbulent flow as presented in [7]. To verify the results of this theoretical equation, two commercially available CFD simulation software solutions are used: Ansys and Siemens NX. For each macro-element simulation, various operational and geometric conditions are considered [10]. These simulations provide the pressure loss and heat transfer coefficient (htc). Using these results in combination with the results of the macro-models, the macro-elements are verified. The result of CFD simulation of a macro-element can be seen in Figure 2. Verification was generally proved with flow $1 \times 10^{-3}[\mathrm{~m} 3 / \mathrm{s}]$ with parametric variable dimensions. The graph in Figure 3 shows a comparison of CFD and macro-model computation. As can be seen, the results are very similar. The results of a specific case are shown in Table 1.
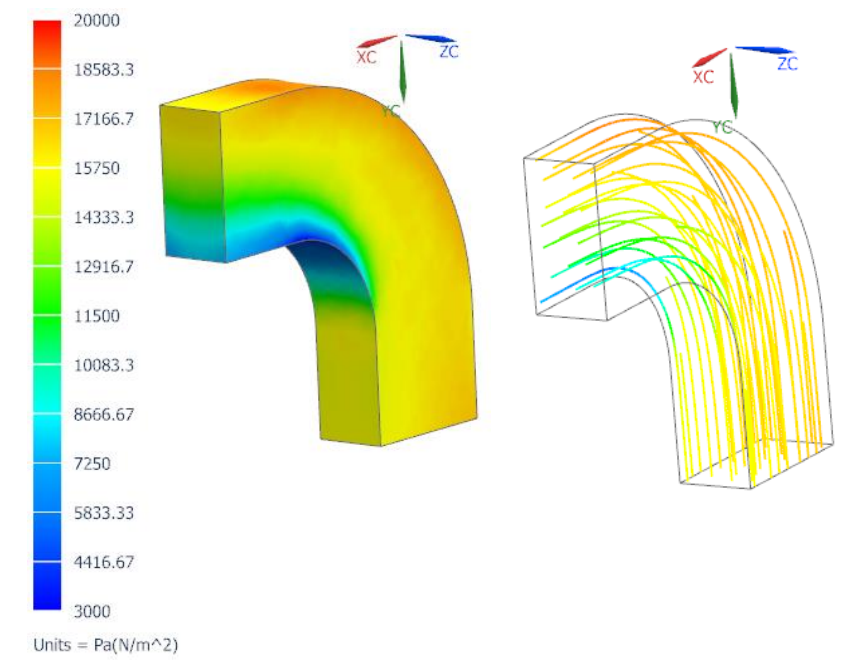

Fig. 2. CFD simulation of total pressure in flow in rectangular elbow

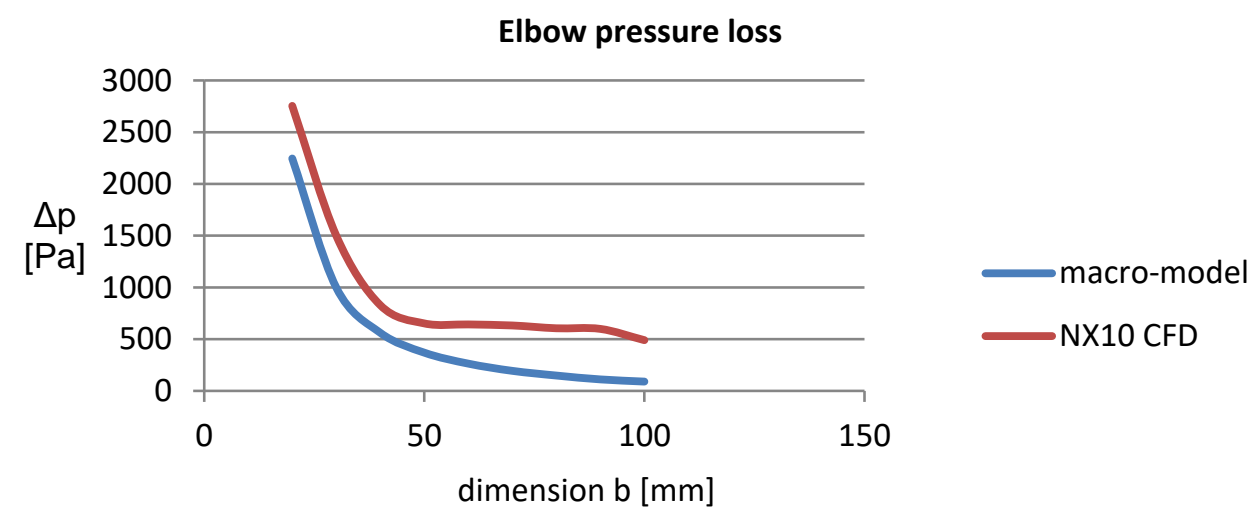

Fig. 3. Comparison of macro-element computation and CFD simulation

\begin{tabular}{|l|l|l|l|l|l|l|}
\hline solver & section & dim.a $[\mathrm{mm}]$ & dim.b $[\mathrm{mm}]$ & Radius $[\mathrm{mm}]$ & Flow $[\mathrm{m} 3 / \mathrm{s}]$ & Pressure loss [Pa] \\
\hline NX10 & Rectang. & 10 & 20 & 25 & $1 \times 10^{-3}$ & 2874 \\
\hline DD & Rectang. & 10 & 20 & 25 & $1 \times 10^{-3}$ & 2245 \\
\hline ANSYS & Rectang. & 10 & 20 & 25 & $1 \times 10^{-3}$ & 2950 \\
\hline
\end{tabular}

Table 2. Results of computation of elbow with rectangular section 


\section{Thermal field computation}

The cooling characteristic is defined by thermal field computation. A similar approach as for pressure loss is performed. The element which performs heat transfer is examined. Heat transfer by convection is governed by the value of the heat transfer coefficient $\alpha$ or $h\left[\mathrm{~W} / \mathrm{m}^{2} \mathrm{~K}\right]$. The value of $\mathrm{h}$ depends on different quantities, including distinct physical characteristics of the fluid in question. Those are the isobaric specific heat (in $\mathrm{J} / \mathrm{kg} \mathrm{K}$ ), the thermal conductivity (in W/m $\mathrm{K}$ ) and the dynamic viscosity (in $\mathrm{kg} / \mathrm{ms}$ ) [6,7]:

$$
\begin{aligned}
& h t c_{\text {convect }}=N u_{D} \frac{\lambda}{D} \\
& N u_{D}=N u_{D}\left(R e_{D}, P r\right)
\end{aligned}
$$

htc $\mathrm{convect}_{-}$- heat tranfer coefficient for heat convection in cooling channel

$\mathrm{Nu}$ - Nusselts number

Pr - Prandtls number

$\mathrm{D}$ - hydraulic diameter

$\lambda$ - heat conductivity

\subsection{Thermal phenomena in a motorized spindle}

A spindle of a milling machine was chosen as an example of thermal phenomena. The motorized unit of a spindle of a milling machine consist of a few main parts which affect the thermal behavior of this assembly. [7]

- heat sources in the stator

- heat sources in the rotor

- heat sources and friction in bearing

- heat sources and friction in air gaps

- heat transfer between shaft and rotor

- heat transfer between housing and coolant

These effects are investigated.

\subsection{Temperature field}

Given an element with a constant wall temperature as boundary condition, the temperature at position and the wall heat flux can be calculated using the solution of the corresponding partial differential equation (PDE):

$$
\begin{aligned}
& \mathrm{T}(\mathrm{x})=\mathrm{T}_{\mathrm{w}}+\exp \left(-\frac{\mathrm{U} \cdot \mathrm{x} \cdot \mathrm{R}_{\mathrm{th}}}{\mathrm{c}_{\mathrm{p}} \cdot \dot{\mathrm{m}}}\right) \cdot\left(\mathrm{T}_{\mathrm{in}}-\mathrm{T}_{\mathrm{w}}\right) \\
& \mathrm{Q}_{\mathrm{w}}=\left(\mathrm{T}(\mathrm{L})-\mathrm{T}_{\mathrm{in}}\right) \cdot \mathrm{c}_{\mathrm{p}} \cdot \dot{\mathrm{m}}
\end{aligned}
$$

$\mathrm{T}_{\mathrm{w}}$ - Wall temperature

$\mathrm{T}_{\mathrm{in}}$ - Inlet temperature (outlet temp. of the prev. element)

$\dot{\mathrm{Q}}_{\mathrm{w}}-$ Wall heat flux

$U$ - Profile circumferential length

$\mathrm{R}_{\mathrm{th}}$ - Thermal resistance between the wall and the fluid

$c_{p}$ - Specific heat capacity of the fluid

$\dot{\mathrm{m}}$ - Mass flow rate through the element

$\mathrm{L}$ - Element length

The conductive thermal resistance $\mathrm{R}_{\mathrm{w}}$ of the wall and the surface $A$ and htc $\alpha$ on the inside of the element:

$$
\mathrm{R}_{\mathrm{th}}=\left(\frac{1}{\mathrm{R}_{\mathrm{w}}}+\frac{1}{\alpha \cdot \mathrm{A}}\right)^{-1}
$$

\subsection{Thermal resistance of a wall}

Thermal resistance is calculated as:

$$
R_{w}=A \cdot \frac{\lambda}{\delta}
$$


$\delta-$ Thickness of the wall

$\lambda$ - Thermal conductivity of the wall

A - Surface of the wall

For a cylindrical element, the thermal resistance of the wall is calculated as follows [3]:

$$
R_{w}=2 \cdot \pi \cdot L \cdot \frac{\lambda}{\ln \frac{r_{o}}{r_{i}}}
$$

$r_{o}$ - Outside radius of the element

$r_{i}$ - Inside radius of the element

\section{Verification of thermal-field computation}

Figure 4 shows the results of a CFD simulation of a macro-model. The CFD simulation in the picture shows temperatures in the housing and temperatures of the cooling fluid. In this comparison, the flow around the model was tested. The bearing unit simulation consists of a heat source which substitutes heat loss of bearing, in this case 800[W]. Cooling is provided by water with a flow of $0.4[\mathrm{~kg} / \mathrm{s}]$.

The macro-model of the flow-around computes the heat transfer with good precision as can be seen in Figure 6. The temperature of output water is almost identical as computed by CFD, shown in Figure 5. Also, other computed temperatures of the wall and bearings are similar, given in Figure 6. The macro-model computation provides the correct information dependent on parametric dimensions, flow of coolant etc.

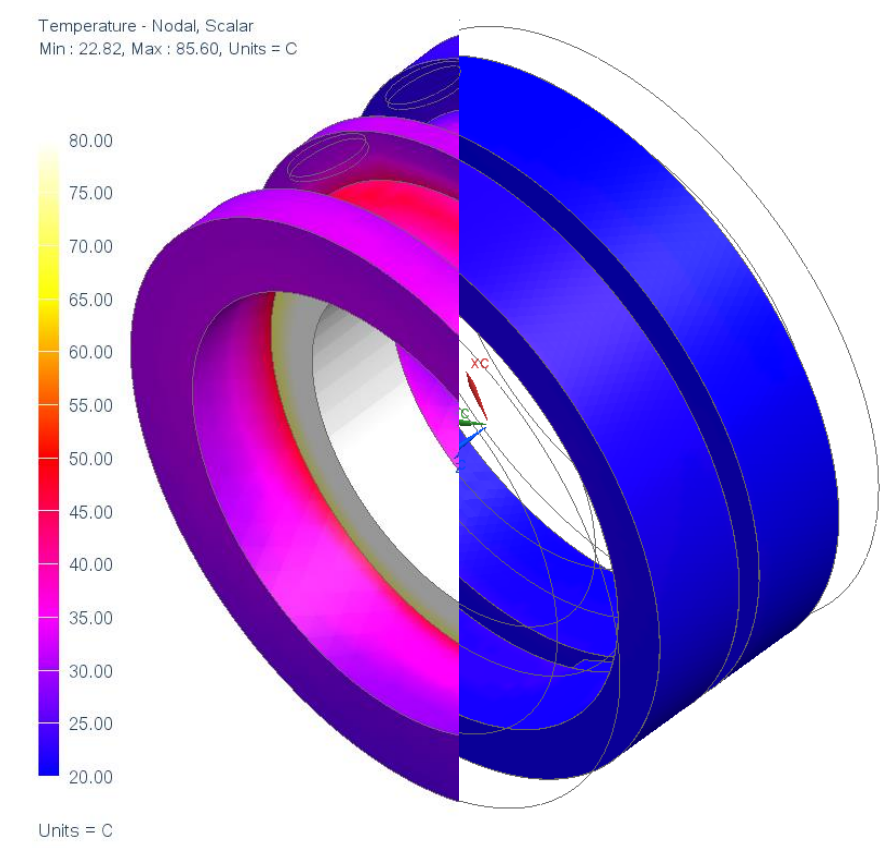

Fig. 4. CFD simulation (NX10) of temperatures of cooled bearing housing

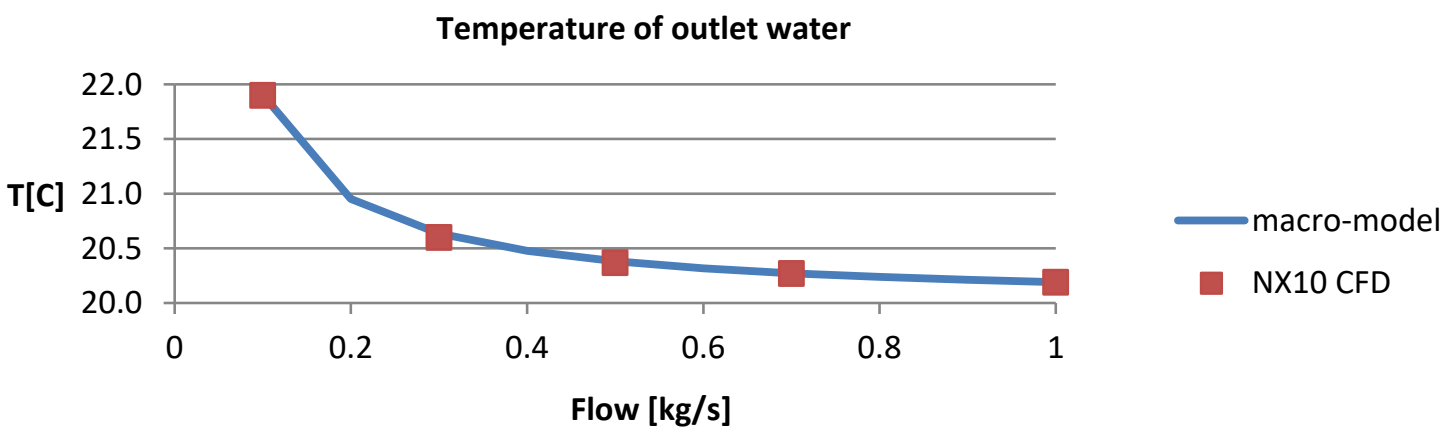

Fig. 5. Comparison of CFD and macro-element simulation - temperatures of outlet water 


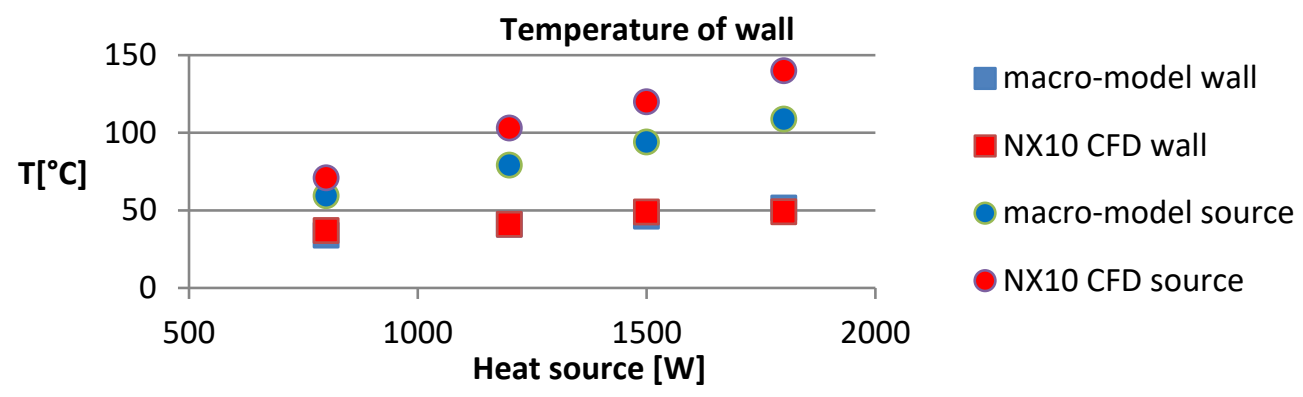

Fig. 6. Comparison of CFD and macro-element simulation - temperatures of wall and heat source (bearing)

\section{New tool}

The interface for the macro-element method computation is a tool called DuctDesigner. This tool was developed by the Institute of Machine Tools and Manufacturing (IWF), at ETH Zurich (the Swiss Federal Institute of Technology in Zurich). A Comparative calculation of the same cooling circuit performed by using the macro-element method provides results almost immediately. Results are shown in the graph in Figure 7. The simulation of a complex cooling circuit of a motorized spindle unit was performed. Figure 8 shows the results from a CFD simulation of the cooling circuit. Macroelement computation is shown in Figure 7. It shows pressure losses, temperatures and the heat transfer coefficient along the path of the cooling circuit. Pressure decrease can be seen in the graph, with an overall pressure loss of $3 \times 10^{5}[\mathrm{~Pa}]$. It also shows the results of temperature computation and heat transfer coefficient computation. Temperature results are given in Table 3.

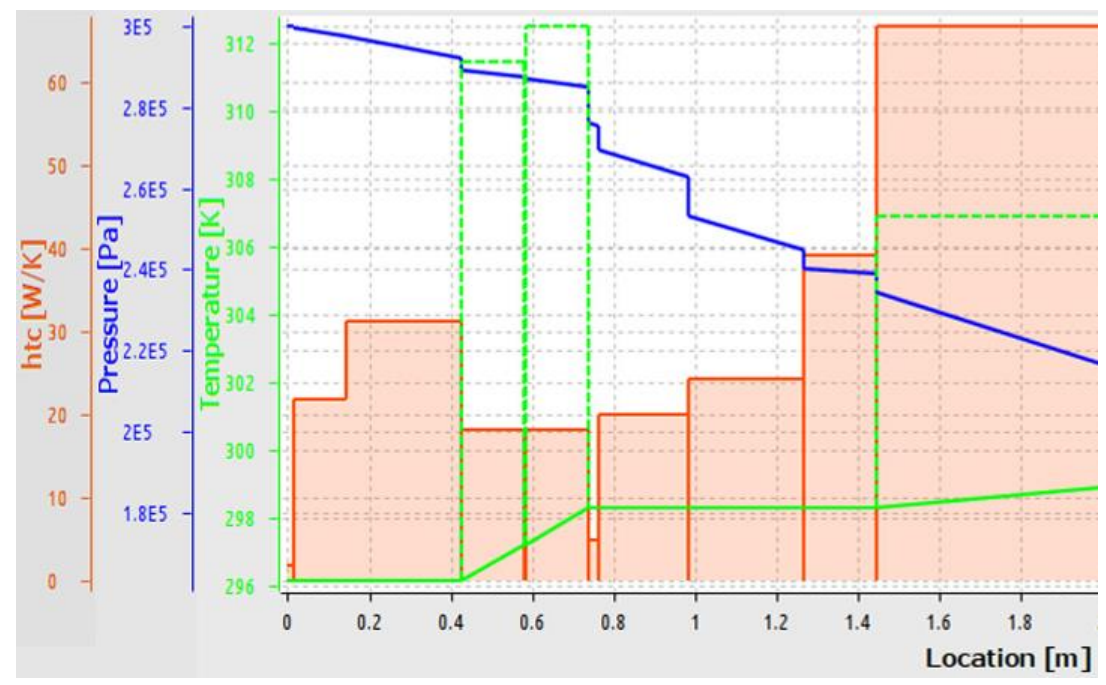

Fig. 7. Graphical output of temperatures, provided by DuctDesigner [1]

Setup

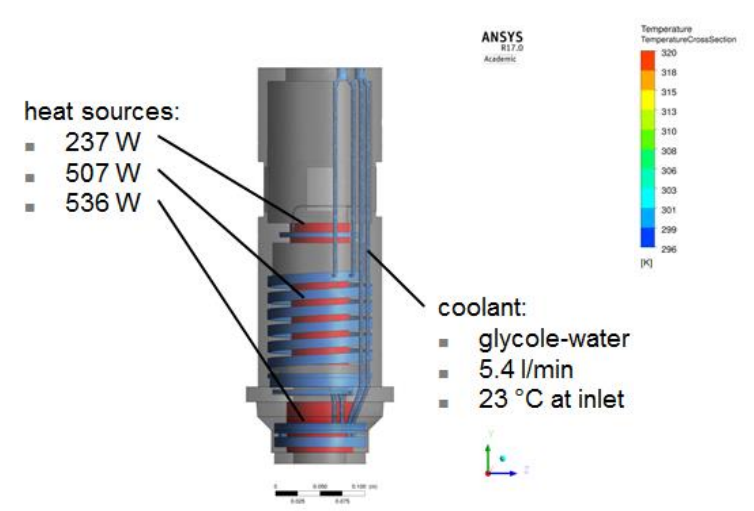

Solution

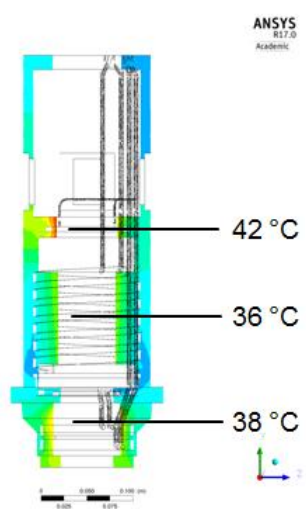

Fig. 8. Setup and solution of CFD simulation of motorized spindle unit, solved by ANSYS [1] 


\begin{tabular}{|l|l|l|}
\hline & Ansys CFX & DuctDesigner \\
\hline Bearing back & $42^{\circ} \mathrm{C}$ & $42^{\circ} \mathrm{C}$ \\
\hline Coil & $36^{\circ} \mathrm{C}$ & $34^{\circ} \mathrm{C}$ \\
\hline Bearing front & $38^{\circ} \mathrm{C}$ & $37^{\circ} \mathrm{C}$ \\
\hline
\end{tabular}

\section{Discussion}

Table 3. Results of CFD Ansys simulation and macro-element computation

Temperature field computed by macro-elements is pretty same as CFD simulation. Temperature obtained by macroelements is a function driven by a few input parameters (flow, fluid properties, channel dimensions etc.). It causes faster computation then CFD, which operates with many parameters of every single finite element.

Macro-element computation does not provide detail results, because of these facts. It provides required information, corresponding the design process. Comparison of method is shown in the Table 4. The table shows main differences between CFD calculation and macro-element prediction.

\begin{tabular}{|l|l|l|l|l|l|}
\hline & Prepare time & Comp. time & Temp. Comp. & Result deviation & Costs \\
\hline CFD & 1 hour & $>600 \mathrm{~s}$ & full & $<5 \%$ & High \\
\hline Macro-model & $1 / 2$ hour & $<1 \mathrm{~s}$ & partial & $<20 \%$ & Low \\
\hline
\end{tabular}

\section{Conclusion}

Table 4. Comparison of CFD and macro-element method

Overview of a design of a heat loaded machine was done in this paper. Macro-element method was integrated into a design and simulation process. Principles of the decomposition of a complex case to elementary case was described. The usability of the improved DuctDesigner software is demonstrated.

Its Macro-element calculation provides less calculation cost, shorter time configuration and no high skill requirements of users, as can be seen in Table 4. At this point, the concept of macro-elements is not a substitute of CFD or FEM, but it is an important addition to the existing design process. Similar results of CFD calculation and macro-element calculation verify precision of element computation. Results of this research should be verified by experiments. Experiments are included in plan.

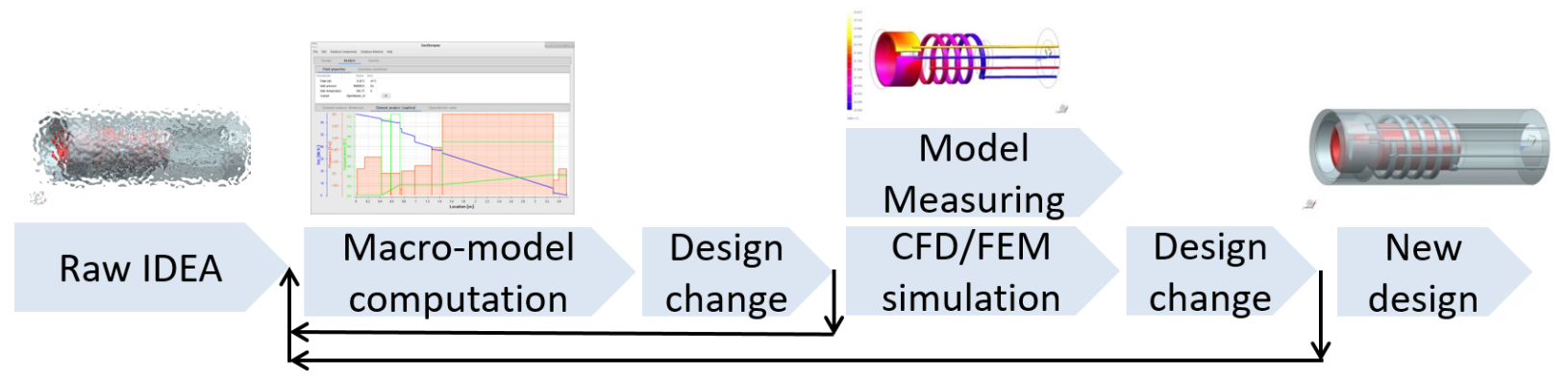

Fig. 9 Implementation of the macro-element prediction into design process

\section{Outlook}

A systematic verification of the existing macro models is thus required, to improve the performance of these models. Experimental measurement of single macro-elements and complex systems simulated by macro-elements is also required for verification. The main potential is identified in the possibility of using the method in a wide range of applications, in the prediction of parameters of a flow, thermal transfer effects and cases of heat loaded machine parts. Obtained data will be used for a research focused on compensation of thermal displacements of milling centres. Macro-element methodology will be optimize for prediction of thermal field in the spindles of large milling machines.

\section{Acknowledgement}

The project LO1502 'Development of the Regional Technological Institute' is carried out under the auspices of the National Sustainability Program I of the Ministry of Education of the Czech Republic 


\section{References}

[1] Marek, V., Züst, S., Wegener, K., 2017, Thermal effects in fluidic cooling system of a spindle based on macro models, MMSciene Journal, in print

[2] Züst, S., et al. Model based prediction approach for internal machine tool heat sources on the level of subsystems, 3rd CIRP Global Web Conference, 2014, CIRP 28 (2015)28-33

[3] Bergman, T. L. a Frank P. Incropera. Fundamentals of heat and mass transfer. 7th ed. /. Hoboken, NJ: Wiley, c2011. ISBN 9780470501979

[4] Stephan, P., VDI-Wärmeatlas. Berechnungsunterlagen für Druckverlust, Wärme- und Stoffübertragung. SpringerVerlag, Berlin, Heidelberg, 2006. ISBN 3540255044.

[5] Weber, J., Weber, J., Thermo-energetic analysis and simulation of the fluidic cooling system of motorized high-speed spindles Institute of Fluid Power, Dresden University of Technology, 01062 Dresden, Germany

[6] Anaratone ,D., Engineering heat transfer. New York: Springer, 2010. ISBN9783642039324

[7] Zahedi, A. and Movahhedy ,M.R. Thermo-mechanical modeling of high speed spindles, Center of Excellence in Design, Robotics and Automation, Department of Mechanical Engineering, Sharif University of Technology, Tehran, Iran accepted 16 January 2012

[8] J. Mayr, J. Jedrzejewski, E. Uhlmann, M. A. Donmez, W. Knapp, F. Härtig, K. Wendt, T. Moriwaki, R. Schmitt, P. Shore, C. Brecher, T. Würz, K. Wegener, 2012, Thermal Issues in Machine Tools, CIRP Annals - Manufacturing Technology, 61: 771-791.

[9] Gerlich, V., Zálešák, M.(2010) Experimental validation of heat transfer model, Annals of DAAAM and Proceedings of the International DAAAM Symposium, 2010, pp. 969-970. ISSN 1726-9679, Zadar

[10] Marek, V.(2016) Basic Research Of Thermal Transfer Simulations, Annals of DAAAM and Proceedings of the International DAAAM Symposium, 2016, pp. 578-585. ISBN: 978-1-5108-3300-5, Mostar 